\title{
Plants, Sites and Political Discourses: A conversation with Artist Zheng Bo
}

\begin{abstract}
YANG Jing ${ }^{1}$
Hong Kong based Chinese artist Zheng Bo is committed to socially and ecologically engaged art. He investigates the past and imagines the future from the perspectives of marginalized communities and marginalized plants. He has worked with a number of museums and art spaces in Asia and Europe, most recently TheCube Project Space (Taipei), the Power Station of Art (Shanghai), the Sifang Art Museum (Nanjing), the Times Museum (Guangzhou), the Cass Sculpture Foundation (Chichester, UK), and Villa Vassilieff (Paris).
\end{abstract}

Yang Jing: The plants are not only associated with your subject, they are actually your medium and material for making art. When did you start to pay attention to the plants around you and take them as your art medium and material?

Zheng Bo: My focus on plants started from 2013. I was brought up in Beijing. In 2012, I moved to Hang Zhou and started to teach at the China Academy of Art. After moving to Hangzhou, I found that this city was characterized by luxuriant vegetation, which looked different from my living environment in Beijing. Meanwhile, I noticed that in Hang Zhou people's conversation topics were different. In Beijing people talked more about politics, but in Hangzhou, people's topics of conversation were more focused on daily life. At that time, I often went to West Lake, Long Jing and Jiu Xi and I started to notice the different plants. In 2013, Xuhui District Government in Shanghai planned to transform the waste land that had been left after the removal of the Shanghai Cement Plant into an art and culture zone. This place today is called West Bund. The government organized the 2013 West Bund Architecture and Contemporary Art Biennale. A curator contacted me and invited me to attend the exhibition. When I went to look at the exhibition space, I initially wanted to find an interior space, but in front of the abandoned factory I found a field of weeds that impressed me. The organizers were planning to change this place into a square where they could hold concerts and other events. I persuaded them to keep the weeds as part of my work. Then, I made the project Plants Living in Shanghai. After that, I continued to make works associated with the plants. As you mentioned, plants are a medium, but my subject was related to politics. Of course, the understanding of politics here has become broader than before. We used to define politics as interpersonal relationships, but I now consider the politics as the relationship between man and everything - for me, specifically the relationship between man and plants.

Yang Jing: Did you first have a certain concept and then you started to use the plants

\footnotetext{
1 Yang Jing is an art researcher from China. She is currently undertaking a post-doctoral research at Department of Music, Art and Culture Studies of University of Jyväskylä, focusing on ecological awareness in Chinese contemporary art.
} 
as a medium and material, or did the charm of plants and the possibilities of plants as a material attract you first?

Zheng Bo: At the beginning, I was not using plants. My use of plants began from 2013. For me, plants are both the material and the concept. Conceptually, plants are connected to my previous work. For instance, after working with plants for a certain time, I realized why I preferred weeds rather than the plane trees along Nanshan Road. This has a conceptual connection with my work concerning the issue of marginality before 2013. I made some works about the marginalized groups and those underclass people; for instance the Philippine domestic workers in Hong Kong. So when I started to work with plants, I also focused on those marginalized plant species, because in a certain sense they are the discriminated and oppressed members of the plant kingdom.

Yang Jing: Yes, I noticed that your plants are mostly herbs, such as ferns and weeds, seldom trees and expensive ornamental plants.

Zheng Bo: On certain level, l've been continuing my concern about the issue of marginality. Regarding materials, two things inspired me. First, in the past, after I completed a work, it remained still, never changing any more. Now I am using living plants, they are growing all the time, so the change is seen even after only a short time. Second, I was not so sensitive of certain factors, such as the exhibition time, the season and the weather. Now if a museum asks me to make an exhibition, I must think when the exhibition time will be - in spring, summer or winter. That has an impact on my work. The growth of plants varies according to the season and weather. When I employed the plants as a material, I didn't decide everything in advance; instead, I used to explore the specialty of material in my working process. In addition, I would like to say, when we use the term "material", more or less we take it as a lifeless thing under our control. I don't look at the plants as a material; l'd rather say that I enjoy working with the plants. For instance, in my Slogan series, I made half the work. After I planted the slogan on the site, the weeds worked on it. Thus, the weeds were not only a material, but also collaborators.

Yang Jing: Did you pay attention to the plants living around you before 2012? I found that you have an abundant knowledge of plants. You know a lot about the character, habit and growing environment of various plants in the city as well as their status in the ecological system. Have you always been enthusiastic about botany?

Zheng Bo: Actually no. The only connection to plants was in my childhood. I lived in the suburban area of Beijing. It is a small town at the foot of a mountain. I used to play on the mountain slope, picking jujube fruits and catching grasshoppers as all kids do. But I never tried to systematically understand the plants, nor did I attend any courses in botany. During these years, I was learning botanic knowledge through making art. In many projects, I cooperated with other people, including ecologists and landscape 
designers. I learnt knowledge of plants through cooperation. I like to study. So, many works are in the form of teaching and learning. For instance, Plants Living in Shanghai was in the form of open course. It was a teaching project. I was learning and then I passed the knowledge I learnt to others. It was an interaction between teaching and learning.

Yang Jing: Your short film Pteridophilia was about the intimacy and equality between men and ferns. We saw flourishing ferns in the tropical forest. A group of young men walked in the forest and had sex with ferns. Why did you choose such a topic?

Zheng Bo: This work was made in Taiwan in 2016. First, I had an interest in erotica in art. In 2004, I made a project titled Watch Porn and Learn English. Then, this short film had something to do with my artist-in-residence experience in Paris last year. After I went to Paris, I asked a worker to make a wooden box for me. I installed it in my apartment and planted some weeds in the box. Every morning when I woke up, I saw them first; every night when I went to sleep, they were what I saw last. They were living with me in the same apartment. I felt that I'm very intimate with these weeds. Then, I started to think under what circumstance a man can be intimate with the plants. My university classmate once said that sex builds intimacy between people. Sex makes you quickly understand a person, even a stranger. Of course, he was talking about the intimate relationship between people. I thought that perhaps I could become intimate with the plants through sex. In 2016, I made this film in Taiwan. In this film, six young men walked into a forest and had sex with ferns. When the actors came for audition, I found that some of them just took the ferns as a non-living tool and they didn't treat the plants equally. I told the actors that as this was a sexual activity, they should take their sex partner equally and they need to think of her/his pleasure. Then the recruited actors tried their best to express the equal feeling; of course it was practically difficult, but we tried to make the relationship feel an equal one.

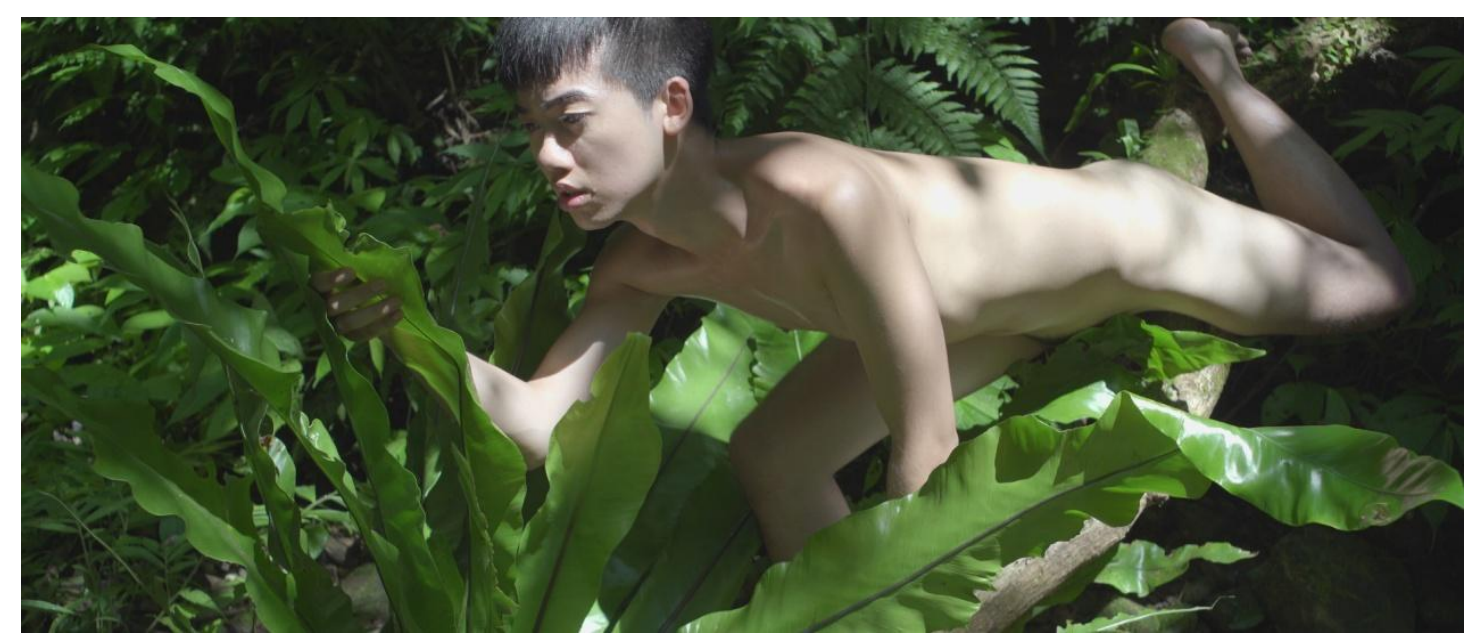

Still from video Pteridophilia, $17 \mathrm{~min}, 2016$, courtesy of the artist 
Yang Jing: This reminds me of Dai Guangyu's performance work, Making Love to the Earth. His body being covered with golden powder, the artist dressed himself as an urban while-collar man in a suit and tie. He took out his penis, grovelled down and kept making love to the earth for about 30 minutes, at the same time reciting the Bible until he was hoarse.

Zheng Bo: I didn't know about this work. Did he do the performance in Chengdu or Beijing? After this work, did he continue this subject?

Yang Jing: It was done in Chengdu. As far as I know, he didn't go on with this subject afterwards. Dai Guangyu's later works were more focused on the concept of water and ink. Water and ink are not only material, but also a concept. He has been expanding the meaning of water and ink. I looked through his works made in recent years. He did much less this kind of ecocritical works. Of course, Making Love to the Earth was to mock the urban people's objectification of nature as a sexual object; it was a critical review of the anthropocentric view. It is different from your film. Back to you, will you continue to work on this topic?

Zheng Bo: Yes. Last year's film was 17 minutes long. l'll go on with the sexuality between men and plants. I'll shoot a short film every year.

Yang Jing: In 2015, you had an exhibition, Weed Party 1, in Shanghai. The exhibition space had three floors that exhibited many of your works, such as Garden, Trees, and Left Right. Later, in 2016, you made the Weed Party 2 exhibition in Taiwan. Is it an ongoing project?

Zheng Bo: Yes, it's an ongoing project. I'm currently making a book which will include all my works since 2013 under the subject of Weed Party. It is a broad subject. Next year, l'll have an exhibition at the University of Minnesota, possibly titled Weed Party Minnesota. Because the issues I refer to are all related to weeds and politics.

Yang Jing: This project interested me deeply. You hand-copied "Shanghai's Wild Edible Plants" published in 1961 and displayed it in the exhibition hall. This reminds me of another kind of relationship between wild plants and human beings. I never really realized that in hard times in human history, those wild plants, especially ferns which were often ignored by people, became people's food and saved them. This work reminds me of the history of the Three Years of Natural Disaster, although we know today that the famine in mainland China between 1959 and 1962 was not a natural disaster; instead, it was caused by a wrong agricultural policy at that time. Thus, this work carries strong political significance. Then I noticed that you juxtaposed the book with the revolutionary photo journalist Sha Fei's news photo titled Young Machine Gunner Growing in Combat, another news photo titled East China Field Army Climb over Mountains towards Menglianggu, a propaganda poster titled People's Postman, and your own photographic work Dream. Weeds appeared in all 
these photos and posters. What is the conception?

Zheng Bo: My inherent logic is quite clear. Since our childhood, all accounts we read about the history of the Communist Party of China are only about the issue of people. It seems that plants had nothing to do with the history of the Communist Party of China (CPC), or the history of $20^{\text {th }}$ century China. When I started to make works, I went to search for material. I thought it would be very difficult; however, once I started to search I found a lot of traces of plants. Of course, my works only presented a small part of it. I saw that from the early time of CPC until today, in every historical stage, the plants were there. I started to understand the relationship between plants and China's political history in the $20^{\text {th }}$ century.

Yang Jing: Yes. For example, the work Left Right is related to the history of 1st National Congress of the CPC.

Zheng Bo: That's right. That was the CPC's early history. Then, in the year when Shanghai's Wild Edible Plants was published, weeds appeared in history too. In the propaganda poster painted in the Cultural Revolution, the artist painted some weeds in the corner. Weeds have been always there, but we looked at them without seeing. My photographic work, Dream, was taken on a construction site in Shanghai; the house is a temporary shelter unit where the construction workers live. The Chinese Dream poster is pasted on the wall of the temporary shelter unit. Weeds appeared in front of the building. They are invasive plants from North America. We know that in recent years, Chinese Dream posters mostly appeared on construction sites where we often saw invasive plants. Because invasive plants hardly have natural enemies, they easily grow on construction sites. The internal logic is very interesting: in the space where Chinese Dream posters appear, you also easily find these invasive species. We can say that the Communist Party or Chinese government is enhancing the Chinese Dream, but they have never noticed the invasive plants in front of the Chinese Dream. It is funny.

Yang Jing: Yes, the existence of these wild plants is out of the ideological control of human society.

Zheng Bo: Or we can say that the CPC didn't realize the importance of the plants. Taking that propaganda poster as an example, perhaps the censors didn't notice these weeds and flowers painted in the corner. The artist had his own taste, but the censors didn't notice that.

Yang Jing: In the two news photos, Young Machine Gunner Growing in Combat and East China Field Army Climb over Mountains towards Menglianggu, the way how plants appeared is also interesting, as they were used as the camouflage on the soldier's body and head. 
Zheng Bo: Yes, I was thinking that the CPC should have had intimate relationship with the plants. The Red Army, the Eighth Route Army and the New Fourth Army were basically guerrilla warriors rather than a well-equipped regular army. They were different from the Kuomintang army. They used to launch guerrilla warfare and tunnel warfare, so using plants as the camouflage was very common.

Yang Jing: I guess that facing a severe shortage of medicine, the doctors and nurses in the communist army had to use a lot of herbal medicines to help the wounded soldiers.

Zheng Bo: I think so too. But I didn't refer to this in my work. Your words remind me about it.

Yang Jing: I also felt the political tension in your later Weed Party 2 project in Taiwan. You hand-copied the Taiwan Wild Edible Plants Catalogue published in 1945. Then you also juxtaposed it with the postcard sent from Japan to support the Sunflower Student Movement in Taiwan, and paintings of Taiwan's tropical flowers which were made by a Japanese artist.

Zhen Bo: The Japanese artist Gobara Koto lived for a long time in Taiwan. In the 1920s, he made a lot of paintings of the tropical flowers in Taiwan, and passed the painting technique on to Taiwanese artists. These three items all reflected the history of the relationship between Japan and Taiwan. The book was published in Japanese, and I hand-copied it in Japanese as well. The publisher was Taiwan Plant Lovers Association, a Japanese organization during Japan's occupation.

Yang Jing: Is this related to the food shortage in Taiwan then? When I saw the topic of edible wild plants, I immediately associated it with the scene that people were eating wild plants during the famine.

Zheng Bo: Yes, it is related. This book was published in the spring of 1945, five months before Japan's surrender. This small book was written in Japanese. The preface states: "At this critical moment of the sacred war, the survival of the empire depends on winning the war on food." It says that the publication of this book would have contribution to the war, and so on. It says that the publishers expected that the book to have an impact. Of course, I don't think this book was for Taiwanese readers as it was in Japanese.

Yang Jing: Quite possibly that people living in Taiwan at that time, no matter whether Japanese or Taiwanese, were facing a severe food shortage, because crops were first used to feed the Japanese army on the frontline.

Zheng Bo: Yes. Taiwan was an agricultural base of Japan at that time. When the Pacific War turned into a white hot war theatre, most crops produced in Taiwan were 
transported to the frontline. Actually, when I was doing this project, I faced the same issue that I had with the earlier project in Shanghai. I was neither Taiwanese, nor Shanghainese, but I hoped that the exhibition would have a certain connection to local history, so I tried to study the historical context. In 2015, I studied the history of Shanghai, in 2016 the history of Taiwan. I found that plants were closely connected to local political history.

Yang Jing: We are coming to the point. Your works are site specific and you have been trying to integrate the plants with local culture and history. How did you manage the dialogue between your work and the site?

Zheng Bo: I've always been concerned about the site specificity, even before I started to work with plants. You know the Chinese proverb "A hare never eats the grass near its own burrow". I think if we understand this proverb from another perspective, it means that it's more difficult to work on a subject that is close to you. If I work on an exotic subject, for example if I make a project about the Amazon in Shanghai, people don't know that well and they can be easily attracted and impressed. If I work on a subject that is very close to them, it requires me to be more cautious. For example, when I was making the project in Taipei, as I was an outsider, I had to be more prudent. As the audiences are Taiwanese; I needed to make them think that my work was meaningful. When I was making the project in Shanghai, I also hoped that the local audience would see that my work is not nonsense. In addition, when the audience see a work that is related to their life, they will be more impressed and more touched.

As for the detailed work, that was not so difficult: just searching for materials on the site and staying with local people, and I think no other ways are needed. When I was doing the project in Shanghai, I searched for materials in Shanghai and communicated with my friends who were familiar with the city. They gave me a lot of ideas. When I was working in Taiwan, I first tried to find ideas at the library of University of Taipei, but I didn't get anything valuable. When I went out, I met a gardener and talked with him. He gave me a lot of help. Another, I went to the Academia Sinica to watch an exhibition about the social movements in Taiwan. I saw the postcards to support the Sunflower Student Movement in 2014. They were sent from Japan. In addition, it's very important to cooperate with local people. Anyway, because I was an outsider, it was impossible for me to know well about the local culture and history in a short time, but it was always possible to find a person who knew about these issues.

Yang Jing: Do you mean not having any preset framework but emphasizing the communication and cooperation with local people?

Zheng Bo: I made projects on different sites, so I might bring my previous experience to a new project, but I never parachuted an existing project to a new place. For 
example, when undertaking the project in Taiwan, because I had done a similar one in Shanghai, I had certain preferences for the project in Taiwan. Again, the cooperation with local people is very important. For example, the gardener I met at University of Taipei worked there for decades; through him, I easily found my way into the study of local history. When I was doing Weed Commons in Guangzhou, I asked the curator to find me a person who knew the local site situation well. He found me a teacher working at Sun Yat-sen University. At the preparatory stage of this project, he showed me and the curator around the site, and I soon became familiar with the area. So, at the beginning, my projects were focused on collaboration with local people.

Yang Jing: Looking through your works, I found that although all of your works are site specific, there are different aspects among them. Some works are created by you as an artist, such as Left Right, Garden and Movements. In these works, you had more control. Meanwhile, you also made a lot of socially engaged projects, such as Weed Commons in Guangzhou, Toad Commons in Taipei, and Plants living in Shanghai. People from different walks of life participated in these projects and their participation played a decisive role. Taking Plants Living in Shanghai as an example, what kind of social impact do you think it has generated?

Zheng Bo: I didn't do a special investigation. After doing this project, I noticed that this work was widely known in art circles. In addition to the field of weeds on site, this project includes an open online course of eight parts. The first lecture was about the wetlands near the Shanghai Science and Technology Museum in Pudong. As far as I know, an NGO, Forest City Studio, was also doing a public education project there about the wetlands. I can't say if my work inspired them or we just happened to come up with the same idea about this subject.

I think it is hard to say that my work generated direct impact; it is difficult to establish such a one-to-one correspondence. But I do believe that my work, together with other NGO actions, let more and more people to recognize these issues. In addition, according to my understanding, some of the impact cannot be seen straight away. For instance, it is difficult to clarify the social impact generated by Dai Guangyu and other artists in the mid-1990s in Chengdu. But I know a young curator in Beijing. In his childhood he lived in Chengdu and saw their work on TV. This might have had an impact on him, but we can't really quantify it.

My work just cut into an issue that many people, no matter whether artists, NGOs, or scholars, were thinking. Together we can bring changes. Of course, in those socially engaged projects, such as the community project in Taipei and the workshop in Guangzhou, we saw certain direct changes in the participants. But for others, I mean the audience who didn't participate in the project, but merely came to visit the exhibition, I can't say if their attitudes were changed by the project. I didn't do any interviews or ask them to fill in a questionnaire about this. 
Yang Jing: In Plants Living in Shanghai, you invited scholars to talk about the issues associated with the plants in Shanghai. For example, He Xin, an ecologist from East China Normal University, introduced the natural wetlands near the Shanghai Science and Technology Museum. Tang Weijie, a humanities scholar from Tongji University, introduced the botany book published in the $20^{\text {th }}$ century. In addition, a writer talked about the trees in Zhabei Park and an architect introduced the landscape plants as texture of the city. I thought that under the roof of plants in Shanghai, there were so many issues and concerns, ranging from ecology, pharmacy, people's daily life, to texts, architecture and urban planning. We hardly noticed the plants living on our balcony. In Luo Xiaoming's lecture, Plants as a Mirror, she presented the different plants on her balcony, revealed the alienation of urban people from green plants under a consumption culture. In your lecture you introduced the different pioneer plants and the interdependence between these species. You also talked how those invasive plants came to Shanghai and how they occupied the urban wasteland. Your introduction about pioneer plants and invasive plants is metaphorical. The plants reflect the different relationship and phenomena in human society. How do you see this?

Zheng Bo: This comes back to our first point that I was not doing a subject associated solely with plants. My works have political concerns, of course, in a broader meaning. I think today there is no non-political thing; no matter whether plants or nature, everything is connected to everything else including to human beings. And once connected to humans, they have to be connected to politics. At least, in the era of Anthropocene era there is nothing on earth which is not related to humans, so we can say that nothing on earth can escape politics. The online lectures in 2013 are a great inspiration for me - through the collaboration with people from different fields, I got into this subject quickly. I saw that plants are associated with ecology, texts, herbal medicine and urban planning, and after that my works advanced. To take one example, Tang Weijie's introduction of the botany books in Shanghai inspired me to make the hand-copied Shanghai's Edible Wild Plant and Taiwan's Edible Wild Plant Category. 


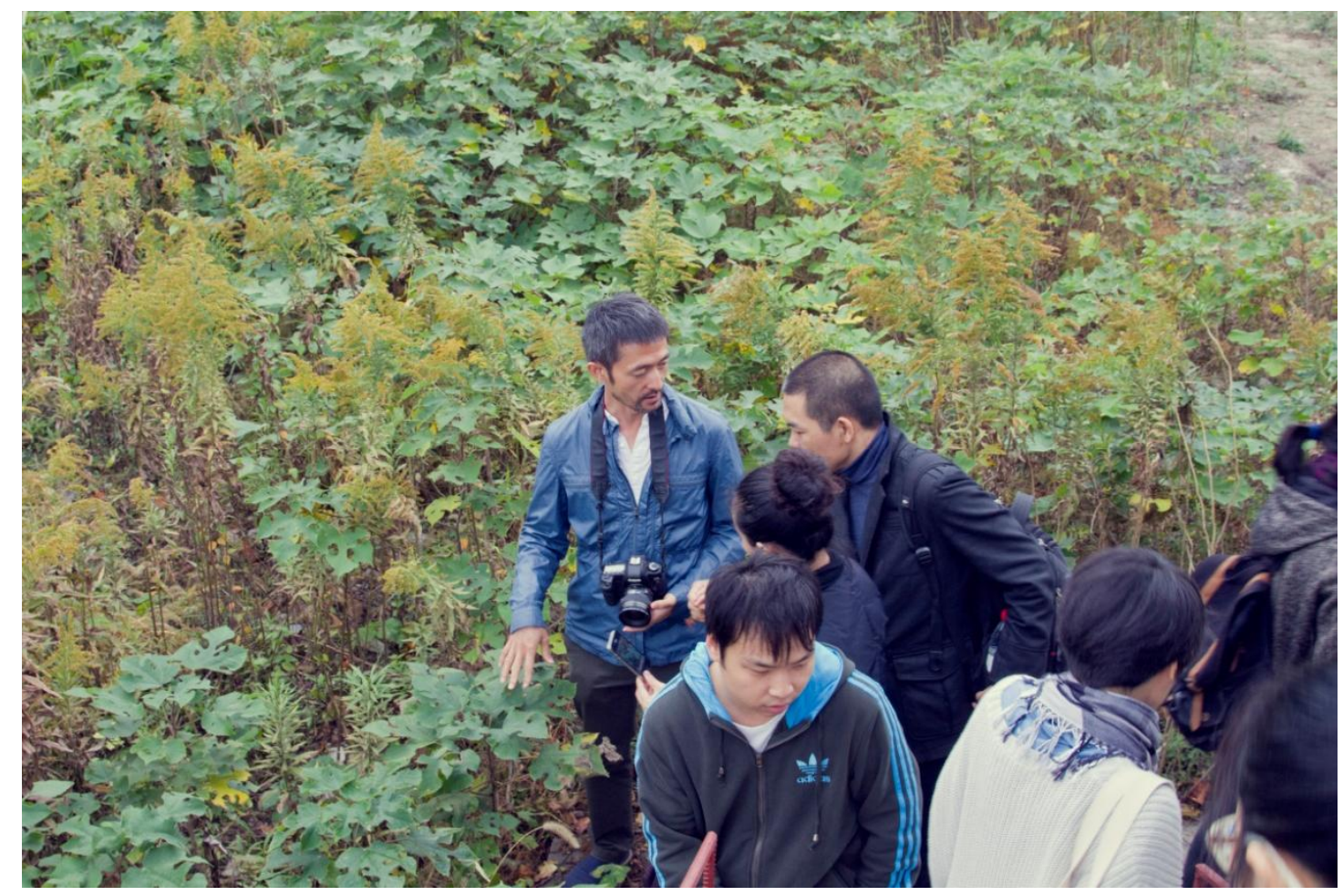

Plants Living in Shanghai, 2013, courtesy of the artist

Yang Jing: You just mentioned the word Anthropocene. In the past decade, Anthropocene has been widely used by researchers from different fields, ranging from geology, biology and anthropology to cultural and art studies. This term was initially used to emphasize that human activities had a decisive impact on the environment of the Earth, for instance the exploitation of natural resources and climate change, which was different from all previous geological eras. What is the main characteristic and function of art in the Anthropocene?

Zheng Bo: I don't know if I can clearly answer your question. Recently, I've been thinking about these issues. The historian Dipesh Chakrabarty inspired me. Before, when we talked about the history of human beings, we excluded natural history. The history of human beings is called History, while the history of nature belongs to geology. These are two separated fields. He believes that since we are living in the Anthropocene, we shouldn't look at the history of humans and nature as two different fields. In fact, my works in recent years also brought up this issue. Is the art museum still a space only for man-made works? Does the border between the art museum and botanic park still exist? Does it still have meaning? Can other living creatures be in the art museum? Of course we accept a stone in the exhibition hall, but how about living animals and plants? Can any living things besides humans be in the exhibition hall? This is a question that the art world in the Anthropocene must face and it is also the most significant difference between art in the Anthropocene and all previous times. Before, when talking about an art work, it had to be an artefact. But can we still hold this idea now? In my case, are these works made by me alone or are they co-made by me and the weeds? 
Yang Jing: In addition to Chakrabarty, have other scholars and artists influenced you more deeply?

Zheng Bo: Hans Haacke is the most inspiring artist for me. If we talk about scholars, first Douglas Crimp whom I studied with has had deep influence on me. Michael Warner is another scholar of great impact on me. Then, Judith Shapiro, the writer of Mao's War against Nature, inspired me a lot. Octavia Butler's work also influenced me. Some Chinese ancient scholars, such as Wang Yangming and Chuang Tzu, had an even greater influence on me.

Yang Jing: What kind of roles can artists play in the Anthropocene?

Zheng Bo: I can only see my own work and I can't speak for other artists, but talking about the role I have played, I have been doing mainly two things. One is to review history, reviewing China's history in the $20^{\text {th }}$ century from the perspective of plants. The other is dreaming the future forms. Different from historians, I am getting into the study of history through an approach that is not so professional. It is unprofessional on one side; on the other side, it means unbounded to any existing restrictive framework. My work aims to explore the various possibilities for the future, not limited in the political or art field, it is more like life experiences in the future world. For example, today we think sexual interaction between men and ferns is ridiculous, but who knows in the future? Maybe it will not be ridiculous.

Yang Jing: Yes. We used to read in sci-fi about humans falling in love with robots. We thought it wouldn't be possible. Today, with the fast development of artificial intelligence and robot technology, this is becoming reality. Perhaps, in the near future, everybody could have a personal tailored perfect robot lover? Human history and modern science and technology are undergoing a great change - something that we thought impossible might come much earlier than we thought.

Zheng Bo: I more and more feel that even though there is still a border between scientists, NGO workers and me, the borderline is not as obvious as before. There is much more communication between people from different fields than there was 20 or 30 years ago. Several weeks ago, I went to Shenzhen to attend the International Botanical Congress which is been held every five years. I sat in on the congress. The research projects undertaken by the scientists deeply inspired me. I feel today that people from different fields and disciplines are influencing each other at unprecedented speed and in unprecedented depth.

Yang Jing: Yes, today, scientific development is characterized by cross- and trans-disciplinarity. The fence separating different subjects is being broken. So, how would you define yourself? 
Zheng Bo: I make art, undertake research work and teach. My creation, research and teaching are mingled together. There is research and teaching in my art work; many works were undertaken in the form of workshops, such as the exhibition in Shanghai. I'm now planning next year's exhibition. I think I could make my art work part of my teaching project. So, the art work is no longer a piece of work, it is instead a teaching tool to be used for the workshop course. I suppose what I have done these years was to integrate creation and research, integrating teaching and learning.

Yang Jing: I have a question about Socialism Good. This slogan first emerged on the Chinese mainland in the mid 1980s and then was placed on Tiananmen Square in 1991. How do you get the idea to transplant the slogan to the contemporary UK, a totally different time and space?

Zheng Bo: First, in contemporary China, we hardly hear this slogan anymore; even the CPC doesn't mention socialism any more. But in the UK, the British Labour Party led by Jeremy Corbyn has written the minimum wage proposal into their 2017 election platform. He has been proposing some socialist policies. Socialist ideology was coming back to many Western countries. I don't think it is so weird to plant this slogan in the UK. In the USA, before the election of last year, nobody would openly talk about socialism. But Bernie Sanders brought this word back to mainstream political discourse. He changed it into a hot word. Before, even those leftist politicians wouldn't use this word; if they were called socialists, they would have denied it. Bernie Sanders didn't deny that he was a socialist and he had a lot of supporters; therefore socialism, even though it was a taboo, has become again a rational and legitimate word.

However, in China today, socialism has become a taboo. Almost nobody would say that he still believes in socialist ideology. If somebody says so, everybody laughs at him and thinks him out of time. Transplanting this slogan to the UK means a transfer of the time and space of speech. This slogan is planted in a public green space, the weeds will grow and with the passage of time, the slogan will change and finally disappear. I also planted another slogan in Shenzhen, the motto of the French Revolution - Liberty, Equality, Fraternity. In Shenzhen the slogan disappears faster because Shenzhen is a tropical land, and there the plants grow fast. The change of slogan in the UK is much slower. This depends on the weather and time. Ancient artists needed to consider these issues when making art; for example, Michelangelo had to often think of the time the paint took to dry when he was painting the Sistine Chapel. In modern times artists think much less about these issues. But now I have to consider them again.

Yang Jing: What will be your plan for future projects?

Zheng Bo: l'll continue working on Weed Party. The topic of weeds and politics is quite broad. Working on this for several years, I now have a lot of ideas and questions. I think this project might last for ten years. For example, you just mentioned the 
relationship between weeds and the crisis in human history, such as famines, and how the plants will emerge in more specific political activities in the future. I'm thinking about these issues through my creations. I did have some very interesting conversations with several artists from former socialist countries. They all responded very passionately to my work on plants and communist history. I hope I will have time and opportunity to work in Russia and other former socialist countries on this topic. Anyway l'll develop this project in the following years.

Meanwhile, I never considered the relationship between my work and the works of other contemporary artists and I have never considered my work in the context of contemporary art. Now I am starting to think about this. You mentioned Dai Guangyu's work Making Love to the Earth. Other artists also used plants in their work. I remember that Song Dong did a well-known work Doing Nothing Garden, but did he continue the subject of plants afterwards?

Yang Jing: As far as I know, he didn't. Wang Jianwei also made a project, Circulation Sowing and Harvesting, in the early 1990s, but afterwards, he didn't continue with this topic. Maybe some other artists are making art with plants, but we don't know about them. In fact, this is a strange phenomenon in Chinese contemporary art. Some Chinese artists have shown strong ecological concern, but using living animals or plants is rarely seen. The reason is unknown. With the advance of my research, I think I can find the answer.

\footnotetext{
i This interview with Zheng Bo was conducted on 8 August, 2017. The interview was originally in Chinese and translated into English by the author. The Chinese transcript was reviewed and approved by artist Zheng Bo and kept in the possession of the author.
} 